\title{
Found in Translation: Bringing Reversal Theory to Design for Play
}

\author{
Mathieu A. Gielen \\ Delft University of Technology
}

\author{
Lieselotte van Leeuwen \\ University of Sunderland
}

\begin{abstract}
In the design of objects for children's play, support from psychology is often sought in general developmental overviews, typologies of play, and age-related performance and preference descriptions. These sources may give an insight into global aspects of child development but have limited utility for understanding the situated motivations of an individual child. Theories that take an experiential view on behavior, such as reversal theory, have the potential to feed designers with a perspective on the dynamics of children's personality, changing motivations and emotions. The potential contribution of reversal theory to design for play was explored in practice: postgraduate students cooperated with design tutors and psychology tutors during a design course to create an object for children's play informed and inspired by reversal theory. Over three consecutive editions of the course, we gathered experiences in supporting idea development for play using reversal theory. Results of the project are presented in form of criteria for adequate framing of the theory in the context of design for play and the resulting modular description of reversal theory. An evaluation of students' incorporation of reversal theory in design ideation is provided and illustrated with examples of design ideas for play.
\end{abstract}

Keywords: Play, reversal theory, design for experience, design ideation, design education

\section{Introduction}

Designing for children's play is a relatively small and specialized area within industrial design education. It requires design skills, but also draws from knowledge of children's development, behavior, and preferences. The use of interdisciplinary knowledge is well established within design methodology (van Boeijen et al., 2013), however, the way in which knowledge from other disciplines is transferred and applied to design has rarely been explored.

The focus of this paper is to use reversal theory in design education as a scaffold for developing ideas for play. Our study aims to increase knowledge of how communication barriers between social sciences and design for play can be lowered.

First, we give a brief outline of the possible roles for social sciences within design processes. Then we review the current practice of the application of social science in the realm of

Mathieu A. Gielen, Department of Industrial Design, Delft University of Technology; Lieselotte van Leeuwen, Dept. of Psychology, University of Sunderland.

We would like to thank the postgraduate students who participated in the course for many discussions and insights as well as for giving permission to publish some of their design ideas.

Correspondence concerning this article should be addressed to Mathieu A. Gielen, Delft University of Technology, Department of Industrial Design, Landbergstraat 15, 2628 CE Delft, The Netherlands. E-mail:M.A.Gielen@tudelft.nl design for play, after which we outline the motivations for using reversal theory.

\section{Design and the Social Sciences}

Traditionally industrial design is described as a problemsolving activity, where the problem of a single person, business, or society is analysed and solved through introducing a product with appropriate functionality (Roozenburg \& Eekels 1995, p84).

A typical design process starts with the phase of problem finding, which leads to the formulation of a design goal and criteria. It is followed by iterations of ideation and assessment with increasing focus on detail. In the initial phase of analysis, designers collect information from, and about, potential users. This process involves a user needs-analysis, trend research, and consulting existing behavioral research. The triangulation of this information results in the description of a solution space that determines both the constraints and degrees of freedom for product development.

Increasingly, the goal of design is not only problem solving but also opportunity finding. This allows for products and services to be created that not only solve a specific problem but also add to the quality of life of the user (van Boeijen et al, 2013; Martin \& Hanington, 2012). Industrial designers have come to realize that products, apart from performing a task, function in the context of people's daily lives and potentially fulfil a much broader role. Hence the attention for design ethnography (Crabtree, Rouncefield and Tolmie, 2012; van Dijk, 2010); experience and emotional appreci- 
ation of products (Schifferstein and Hekkert, 2007); social design and design for behavior change (Tromp, 2013). Designers increasingly cooperate with social scientists to realize these extended ambitions and transfer knowledge between the domains.

\section{Social Sciences in Design for Children's Play}

Expanding the focus of design from solving isolated problems to generally enhancing quality of life suits the context of design for free play, where opportunities rather than problems are usually a starting point for idea development. The need to play for the sake of play by its very nature lacks userspecified goals that can be directly translated into a given set of concrete design requirements. For play the motivation and ability to engage, rather than the immediate result and efficiency of the engagement, determines the success of a design (Burghardt 2006, Shneiderman, 2004).

The lack of concrete design requirements for play leads to two problematic tendencies in current design practices.

The first problem is the primacy of performance over experience. We find (both at our own institutions in Western Europe and from design educators around the world) a recurring pattern where the absent goal in design for children's play is replaced by educational and parental goals to support desirable development through play. These goals range from logical reasoning, co-operative behavior, and creativity to the prevention of obesity. Understanding and using play as a vehicle for progress is the most prominent approach to both the psychological study of and design for play in children (Ackerman, 2004; Sutton-Smith, 1997). Design for play has been to a large extent informed by cognitive (Piagetian) and social constructivist (Vygotskian) theories of development and to a lesser extent by psychoanalytical theories such as Eriksson's stages of development (for example Kudrowitz \& Wallace, 2010; Nicolopoulou, 1993; Rogoff, 1990).

The second problematic tendency resides in the simplification of psychological concepts towards typologies of, for example, gender, personality, or descriptions of skills and preferences according to developmental stages (Acuff \& Reiher, 1997). These are mapped to supposed needs of different characters of children such as the rough/push/build/observetypes (de Valck, 1996). Special design tools have been developed to give an overview of developmental stages and corresponding needs and interests of various age groups, e.g. the 'Developmentally Situated Design card set' (Bekker \& Antle, 2011). These aids are popular and widely used in design education related to children's play. They support a somewhat differentiated but rather stereotypical idea of static user groups.

Bekker et al. (2014) argue that attempts to make the link between child development theory and interaction design explicit and operational have so far not succeeded. Several attempts to use psychological theories to explore the rela- tion between playful/pleasurable experiences and the design aspects which lead to them have been undertaken in digital games and interactive design contexts (see, for example, Costello \& Edmonds, 2007; Hunicke, LeBlanc \& Zubek, 2004; Korhonen, Montola \& Arrasvuori, 2009). Korhonen et al. (2009) developed PLEX cards to support the design of playful experiences. The cards contain single behaviors that are experienced as playful, such as e.g. "Captivation - forgetting one's surroundings" drawn from Csikszentmihalyi's flow concept (Csikszentmihaly, 2008) or "Control - dominating, commanding, regulating" drawn from Apter's reversal theory (Apter, 2002). Isolated from the context of the respective theories, these statements might be a useful element within the palette of inspirations that a designer uses but they minimize potentially design-relevant ideas contained in them. One example is the individual dynamic of play preferences and needs depending on temporal and situational contexts.

\section{Reversal Theory and Design for Play}

Reversal theory (Apter, 2002) is a conceptual framework which lends itself to addressing individual dynamics in motivation for play with the potential to spark design ideas for the following three reasons.

First and foremost, embracing the dynamics of behavior allows one to contextualize play within everyday life and draw inspiration from what play might mean to an individual in the context of other, non-play activities. Rather than describing the function of play for normative development, it addresses the function of play for an individual across ages and in differing situations. Metamotivational dimensions and their combinations provide a rich framework from which situated action tendencies and their change can be mapped to the action possibilities design can provide. This is in our view a step away from using static traits as described above. Studying motivation as a dynamic system mirrors current scientific thinking that until now has received little attention in the realm of design for play.

Secondly, taking into account changing interpretations of arousal, design for play can provide opportunities for individual adjustment of excitement.

Thirdly, the concept of protective frames enables a different view on security and risk. The often made observation that play can only take place under safe circumstances (e.g. Burghardt, 2006) has usually been approached by the creation of physical and social safe conditions for play. However, for the subjective state of play to be present, one needs to subjectively feel protected. Apter's concept of protective frames provides a measurable framework for the type and extent to which children feel free to take control in play and act autonomously (Apter, 1991), (see also Figure 7 in the results section). 
Apart from these reasons, reversal theory has the benefit that while being a highly abstract meta theory, it can also be systematically mapped to concrete everyday activities and provides tools to do so. It also explicitly aims to facilitate interdisciplinary application.

\section{Case Study: Bringing Reversal Theory to Design for Play}

Understanding the potential of reversal theory for design as a psychologist is one thing. Effectively communicating this relevance to students of design is quite another. In order to meet that challenge a design tutor, design students, and psychologists embarked on a co-operative teaching project within a Masters course, Design for Children's Play at the Department of Industrial Design of Delft University of Technology. The project aimed to translate reversal theory as a concept addressing the motivation to play into designrelevant terms and to gain understanding on how this would open up a wider solution space for design and provide strategies to conquer this space. The challenge was to avoid often seen oversimplifications and at the same time reach high accessibility for designers. Our aim was to find answers in a practice setting to our questions:

a) how reversal theory concepts can be tailored and presented to facilitate insight and inspiration by designers of products for play;

b) what prevents or enables students of design to apply these concepts.

Preliminary findings from this study have been reported previously (van Leeuwen, Gielen \& Westwood, 2012); in this report the complete process and findings are presented.

\section{Method}

\section{Participants}

Participants were 60 M.Sc. Design students who took the course Design for Children's Play in one of three deliveries during 2011-2012. Students worked in pairs and had access to a design tutor and two research psychologists with expertise in reversal theory and the application of psychology to design contexts.

\section{Design and Procedure}

The project followed a "research through design education" approach in which the application of theory was observed in practice. Reversal theory was introduced within the educational setting of the Masters course on design for children's play, with a course load of 80 hours. Three deliveries of the course were included in the study. Each course contained a lecture, a discussion meeting, at least two design feedback meetings and the possibility for contact through email, as shown in Table 1.

The method of presenting the theory was extended from Course Delivery 1 to 2 and 3 on the basis of students' designs and feedback in Delivery 1. A design-focused introduction of reversal theory in four modules derived from experiences in Course 1 was applied in delivery 2 and 3 (these modules will be described under results).

\section{Analysis}

The following data, which resulted from interactions between design students, the design tutor, and the two research psychologists, were used to determine the structure and depth of information presentation:

- the concept material provided by the tutors (lecture notes, literature and web-based material);

- the anecdotes presented by the students of their memories of personal experiences with reversals;

- transcripts of real time and e-mail based question-andanswer sessions between students and psychologists based on the concept introduction;

- transcripts of three-way interaction between design students, design tutor, and psychology tutors;

- initial and finalized idea sketches together with notes of idea-specific discussions between students, tutor, and psychologists;

- final reports describing the design process and design concepts.

This documentation was also sifted for insights into the needs and problems of design students when trying to "translate" and embed social science content into the context of design for play.

\section{Results}

Our results are split in two parts, following the dual aim of the research. The first part deals with tailoring reversal theory to design for play and presents a modular composition of reversal theory concepts. The second part focuses on the process of communicating reversal theory to design students and lists a number of issues in bridging disciplines.

\section{Results Part One: Tailoring Reversal Theory to Design for Play}

As part of our observation of the design students' employment of the theory, we assessed their understanding of RT concepts, leading to insights regarding possibilities and constraints to using RT in design education. As a consequence, after Delivery 1 of the course the following criteria for the presentation of reversal theory concepts to design students were formulated:

- link description of psychological concepts immediately to design examples to facilitate practical understanding;

- create a hierarchy and prioritization of information to enable grasp of complexity and integration of different aspects; 
Table 1

Elements of and Differences between Course Deliveries

\begin{tabular}{ll}
\hline Course Delivery 1 (20 Students) & Course Delivery 2\& 3 (20+20 Students) \\
\hline SESSION 1: LECTURE & In addition to Delivery 1: \\
1 hour introductory lecture about reversal theory & Module-based description of reversal theory; \\
& $\begin{array}{l}\text { Students were invited but not obliged to use reversal } \\
\text { theory as a design tool }\end{array}$ \\
\hline
\end{tabular}

SESSION 2: DISCUSSION

Discussion of students' description of individual experiences of reversals;

Question and answer session between students and psychologists based on the concept introduction;

E-mail based summary of the discussed reversal theory concepts

DESIGN TASK introduced:

Design of a play object for an age group anywhere from 0 to 14 years
In addition to Delivery 1:

Students were asked to choose one module of reversal theory as a starting point for ideation and involve the other modules one by one during idea development

\section{SESSION 3: DESIGN FEEDBACK}

Discussion between pairs of students, tutor and psychologists about initial idea sketches and their relations to reversal theory

\section{SESSION 4: DESIGN FEEDBACK}

Discussion between students, tutor and psychologists of final idea and its relation to reversal theory

\section{REPORT}

Each student duo handed in a report describing the design process.

Overview of working process indicating contact moments between participants; the initial set-up is listed in the left row while the right row lists changes to the set-up in the second and third delivery.

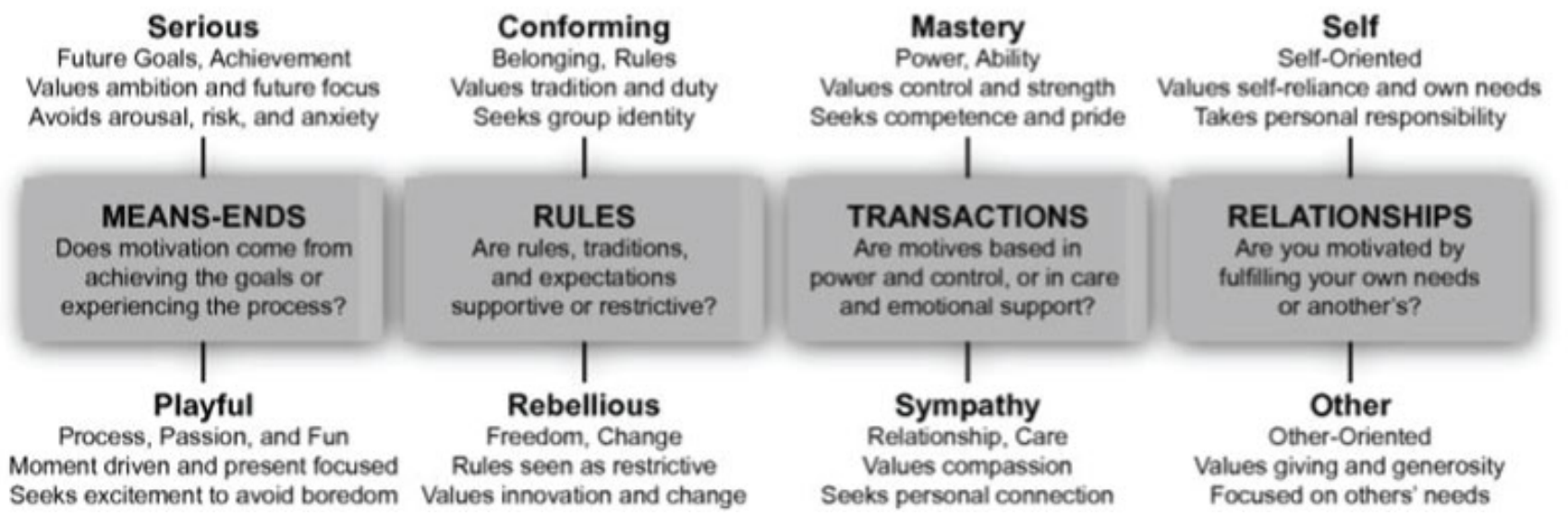

Figure 1. Four dimensions of everyday motivation (Kerr \& Apter, 1991)

- highlight dynamic aspects of behavior as compared to static characteristics;

- highlight criteria for design based on individual motivation rather than performance;

- support a research-by-design approach, i.e., the presentation should become an object with differing functions during design iterations and modes of interaction.
These criteria were applied in the second and third delivery of the course. A representation of reversal theory in four interlinked modules was made, each module representing one sub-concept within reversal theory.

Module 1: Play and dimensions of experience. According to Apter (2002/2007a) any action is the result of the interplay of four pairs of alternative motivational states (shown in Figure 1). Reversals take place when motivation 
switches from one alternative to the other - e.g. from being serious to being playful. At any point in time we occupy a position in this 4-dimensional space and feel more or less good about it. The relative attention to the dimensions might differ over time, i.e. a motivational state might be determined by one dimension more than others. The emotions that accompany a state provide an individual with an evaluation which will guide action to sustain or change the current situation. High positive feelings in a particular state are indicative of optimal circumstances for action in that state. Correspondingly negative feelings indicate suboptimal or adverse conditions for action in a particular motivational state. This also means that depending on a motivational state or 'mood', the same activity or event can be experienced as pleasurable or right out annoying (loud music is a good example).

Everyday experience can be characterized by the changing "coordinates" in that motivational space, the rate of these reversals between alternatives, and changing hedonic tone. Individuals do differ in their overall preferences for certain coordinates in the motivational space and the time they like to spend in them. Apter (2003, p 474) asserts that "we are very different kinds of people at different times in everyday life, and that this is the essence of what makes us human. Personality is dynamic not static: we are more like dancers than statues." The question for design, then, is how objects, environments, and interactions influence the coordinates and their change in this space. Designing for play would mean to create situations and action possibilities in which people are motivated and enabled to engage in a playful way. While this desire is expressed in the serious vs. playful dimension, preferences in the remaining three dimensions are indicative of preferences for certain types of playful engagement.

Dimension 1 - serious vs. playful. This dimension describes the motivation to do whatever is necessary in order to reach a goal (the telic state) vs. being motivated by an activity for its own sake, which is a playful (or paratelic) state. However, the idea that play is without a goal only holds in the sense of goals that are consequential beyond the play situation. For instance the building of a model space ship can be experienced as play motivated by the outcome or the process of making it, depending on the player's preference. However, at NASA the same activity will be mainly experienced as telic because it has consequences for the individual far beyond the activity itself, such as the professional integrity of the model maker or the specifics of the functions to be tested with the model.

The example also highlights that almost any activity can be experienced as serious or playful depending on the motivational state of the actor. The resulting tasks for a designer in the context of play would be to either catch people in a playful mode or make them reverse from a serious to a playful mode. The former would mean to identify situations and contexts in which people are more likely

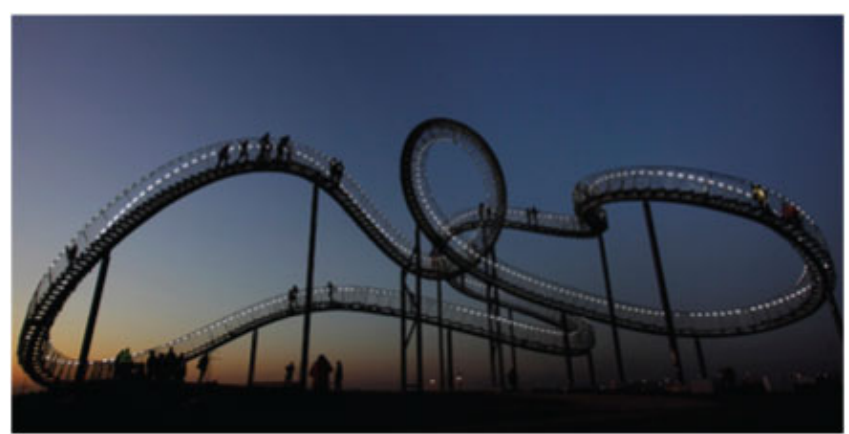

Figure 2. Tiger \& Turtle - Magic Mountain; a walkable sculpture by Mutter \& Genth Duisburg, Germany

to be in a paratelic state (e.g. break times in school and at work). The latter would mean to focus on trying to reverse someone's motivational state to paratelic. An example of the latter would be to reverse people's motivation in the situation of commuting. The VW Musical Stairs project at the Stockholm Metro tries to do this by transforming a subway staircase into a piano keyboard (http://www.youtube.com/watch?v=dN0eabGb-vI)).

A second example is given by The Tiger \& Turtle sculpture by Mutter \& Genth (2011) - shown in Figure 2. A walk over the hill becomes an invitation to artistically shaped playful detours.

Dimension 2 - conforming vs. negativistic/rebellious. This dimension describes the motivation of an individual at a certain moment and in a certain situation to follow or defy rules, to be conformist or rebellious (negativistic). Games provide sets of rules and routines that regulate action and interaction, providing a framework for play. Conforming to this agreement about place, time, roles, and rules contributes to creating structure and safety for individuals to engage in play. The well-known attempts to "bend" the rules are signs of a reversal towards a more rebellious outlook in which the rules are questioned. Rebelliousness is inherent in many forms of play because conventional (or real life) hierarchies are broken down between players (Smith, 2010). Actions that would have negative consequences in real life can be tried out by taking on a role or making decisions in a play frame that would be either impossible or have negative consequences outside this frame.

Two aspects might support idea development: One is the division of control or decision power between designer and player - it ultimately determines to what extent the design supports activity prescribed by instructions and rules or motivates the player to control the content of the play activity. Trying to allow within one play context for more conforming as well as more rebellious experiences could be an interesting focus for design, see Figure 3. The second aspect is the influence of age and culture on what is seen as rebellious. For 


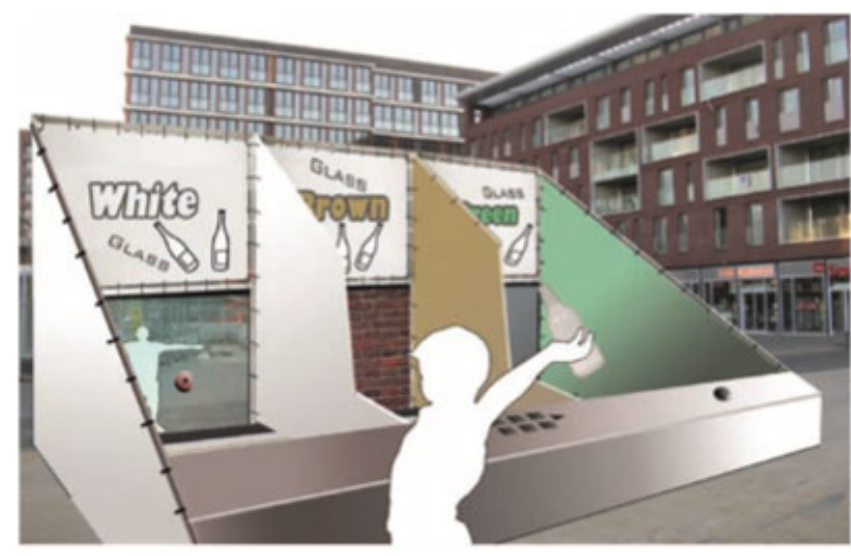

Figure 3. Bottle bank.

Design by Alen Halilovic and Ruben Rosenbrand. Bottle bank is a design for a glass recycling unit in public space. It invites users to throw and smash glass bottles. The design explores rebelliousness as it creates the possibility for primary school age children to perform a forbidden but desirable act (smashing glass) in a conformist context (saving, collecting and recycling of glass). The bravest children stand behind the transparent wall against which the glass is smashed. An interesting side effect of the design is that waste becomes something valuable and scarce. Children that like this sort of play may even go door-to-door in the neighborhood collecting the empty bottles and expose themselves to the potential criticism of their behavior.

example the rebelliousness of an 8 year old is rather different from that of a teenager, or adult.

Dimension 3: mastery vs. sympathy. This dimension describes the motivation for interactions with others or with oneself to be based either on power and control, or on cooperation, sharing and understanding. In a play context this refers to the motivation to master skills, challenge oneself, compete, and dominate vs. the motivation to be part of a shared idea or goal or to allow oneself to concede. Sports like tennis or athletics support the mastery and competition motivation in a relatively pure way. In contrast, team sports have an element of both - supporting one's own team and dominating over the other. Some players might be motivated mainly by team spirit, others mainly by the mastery and competition. Depending on the way the game unfolds, players might reverse from one mode to the other. People can take part in essentially the same activity but with opposite motivations.

From skateboards to games, competition and mastery are a major context for toys in western culture. Cooperative board games based on sympathy rather than on competition have gained popularity recently. The game actions and the goal of winning are not different from any other game. How- ever, the interactions between the players are of a fundamentally different kind.

Supporting mastery or tough competition in explicit balance with co-operation and empathy within one play context is seldom tried. Incorporating reversals between challenging and accepting oneself into design for play could provide a platform for more complex self exploration.

Dimension 4: self-other. This dimension (also described as autic versus alloic) describes the motivation to focus on the self or on others. The motivation to take autonomous responsibility versus following group consensus is part of this dimension. Immersion in playful interaction can mean to either be aware of oneself (autocentric state) or to be aware of others (allocentric state). Applying this dimension to play opens up different avenues: e.g. exploring the meaning and consequences of individual differences vs. commonalities. It may be important to foster awareness of both states. While the need to meet others' expectations and be seen as part of a group in certain ways is already part of many toys and games, there is much less emphasis on supporting the discovery of individual meaning, expression, and preferences within interaction. For example, when dressing up motivated by a focus towards others, costumes identifying known roles or characters would be a likely choice. In contrast, when dressing up motivated by a focus on self, items might be chosen because of a reference to individual preferences rather than social conventions. Analysing the action possibilities of play contexts from both viewpoints will help to create more versatile designs. Seemingly contradictory states can be related to each other through the dynamics of reversal from one state to the other.

Combining the dimensions. Design for play could be guided by choosing to design for the combination of two or more of the four motivational dimensions. For example participating in a flash-mob will be more likely for someone in a motivational state characterized by inclination to be rebellious in a social rather than individualistic way and in which the feeling of sympathy is significant. In contrast, playing racing games is satisfying when motivated by autonomous mastery and toughness. Both situations afford playful engagement but satisfy rather distinct motivational patterns. Another example of a design providing opportunities to act along differing dimensions of motivation is the Triple SeeSaw (shown in Figure 4).

Module 2: Play as dynamic experience. Module 1 addressed the alternative states on four motivational dimensions. Module 2 complements that with an explanation of the dynamics between these extremes. When asking what makes people want to play, Apter's (2007a) reversal theory provides an intricate answer that is based on the combination of a motivational state and arousal. The theory states that any state of arousal can be experienced in either a goal-directed (telic) or playful (paratelic) motivational mode. In a playful 
state of mind, individuals might enjoy danger, incongruity, ambiguity, and challenge. Different levels of arousal are experienced in a complementary manner in the two modes. In a playful state, high arousal is experienced as pleasant, i.e. exciting, and low arousal as unpleasant, i.e. boring. But in a telic or goal-directed state high arousal will be experienced as anxiety and low arousal as relaxing (see Figure 5).

At any point in time reversals from one state to the other can happen. Take the example of consecutive moments of a rollercoaster ride: while queuing one may be looking forward to the ride, then get scared from the screams of people racing by, later be comforted by the sturdy safety brackets, aroused by the beautiful view from the top, terrified by the experience of free fall, finally thrilled by the feeling of having survived this uncontrollable ride. A situation like the rollercoaster does necessarily induce a playful state, but as shown in the example, frequent reversals between telic and paratelic states are likely to occur. However, it would be wrong to conclude that play only happens at the highest arousal states - depending on the situation and mood higher or somewhat lower levels of arousal are preferred within a playful state.

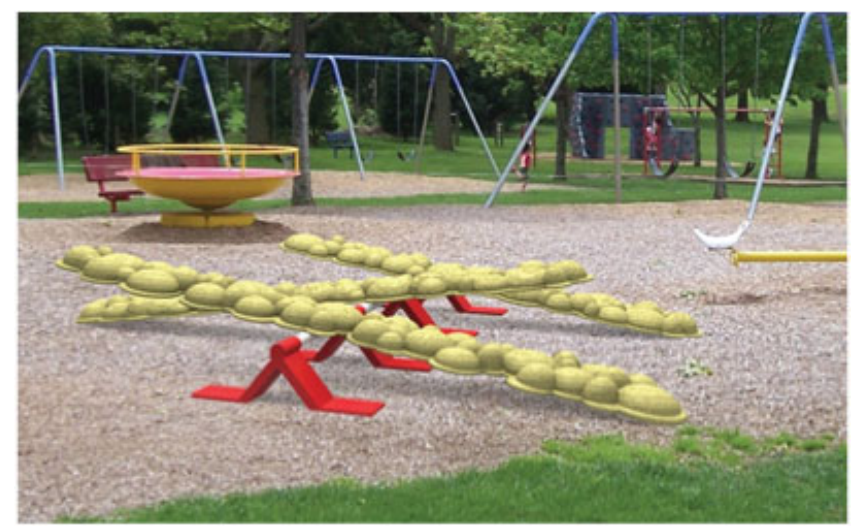

Figure 4. Pebblance, a triple seesaw.

Design by Tim Overkamp. This design idea for an outdoor play object is meant to sit, stand and walk on. It invites users to play with balance. Each seesaw has an uneven surface and a different tipping behavior due to different weight distribution. A user can try out each seesaw separately, try to cross over from one seesaw to the other, or be confronted with other players who cooperate or compete in the balancing act. The necessary level of balancing skills for each of these are quite different, and finding oneself trying and failing, succeeding, being overpowered by others, completely mastering the object can cause many reversals between excitement and mastery, or relaxation and boredom. This object invites players to create different goals and challenges according to different moods and social constellations. In other words, it gives them the opportunity to control their experience.

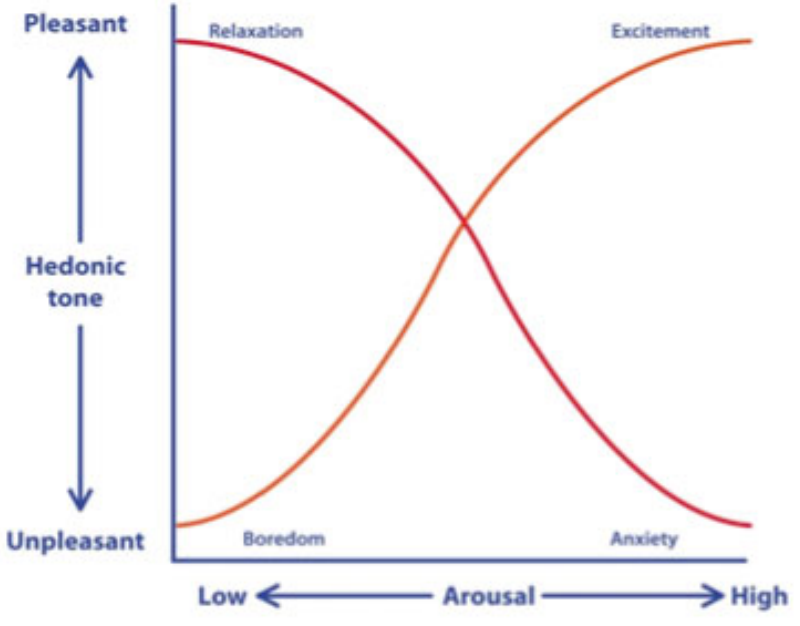

Figure 5. Emotional interpretation of arousal depending on metamotivational states being telic and paratelic. Adapted from Apter (2002), p.19.

When designing for play one can aim to bring about a change from the goal-oriented to the playful at about the same level of arousal. The starting point for design could be a specific everyday activity or situation which has the potential to be experienced as playful but is usually not. Another approach would be to design activities which increase or decrease relative arousal levels within a playful state, such as in the design of a meditative museum experience, shown in Figure 6.

Module 3: Play and experience of control. A rollercoaster ride can result in one individual wanting to immediately repeat the experience and another wanting to never do it again. The difference, according to Apter (2007a, 2007b), lies in the subjective experience of being protected and feeling in control. According to reversal theory, individuals prefer higher arousal in a playful state and avoid it in a serious state. Arousal levels increase, among other ways, through the experience of danger and risk-taking. But from within a protective frame, risks are seen as exciting rather than frightening. Apter (1991, 2007a) describes different levels of experienced (not per se objective) safety or protection as shown in Figure 7.

The confidence frame. is experienced in the presence of imminent danger safety due to trust in one's own capabilities to deal with it, often combined with trust in equipment, low probability, and/or trust in others. This safety-within-danger is experienced as exhilarating. Examples would be the participation in extreme sports or Urban Exploration. Note that the danger can be of any kind, not only physical. For example Urban Exploration can be connected to both a physical as well as a social threat. 


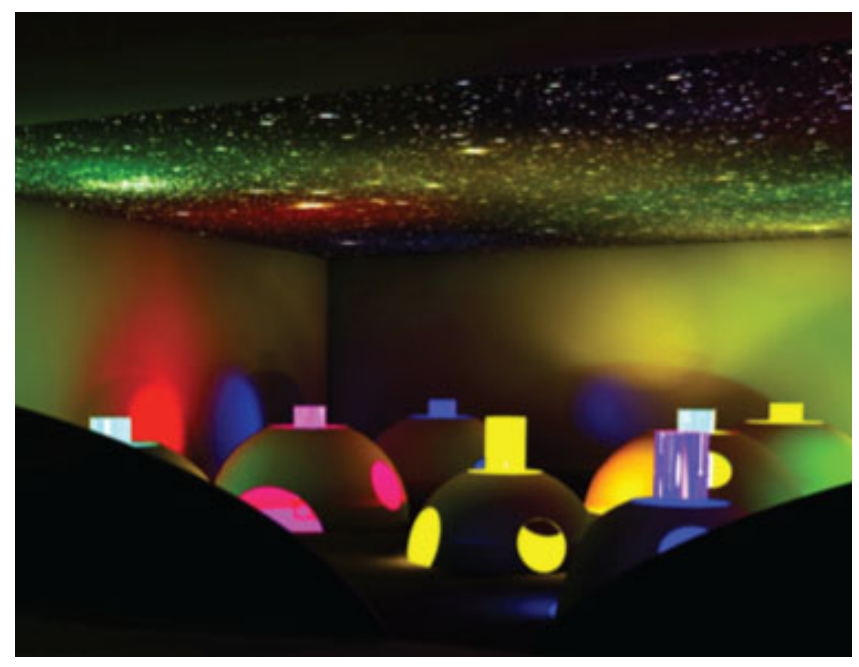

Figure 6. The meditative museum experience.

Design by Kine Handlykken and Nurgul Isik. This museum interior design aims to lower young children's usually high arousal levels at the end of a museum visit but keep them in a playful state. In this idea, a dimly lit room contains a series of small dome-shaped huts, big enough to fit only a few children. Colored lights project from inside the huts, inviting the children to enter them. Inside, long tubular lights change color under influence of human touch - but do so very slowly, like lava-lamps. Children could explore the room running from one hut to the other in search for quick kicks, and gradually discover that the lighting pattern becomes more enchanting when observed and influenced at a slow pace. Thus the design may invite them to adjust their pace and arousal levels; optimal exploration and enjoyment are thus linked to lowering the arousal level.

The safety zone frame. is associated with the absence of experienced imminent danger. An example would be to play a team sport in a sports centre or exploring a museum.

The detachment frame. describes safety experienced through the fact that one is merely an observer of a dangerous situation who empathizes with changing arousal levels but without having to carry any consequences of the actions observed. An example is to empathize with the adventurous moves of the hero in an action movie.

Which of the protective frames is preferred in a playful state does depend on a complex set of situational and behavioral factors. The higher the experienced danger, the higher the chance of loss of the protective frame and with it the reversal to a serious state. What might seem an exciting climb in the mountains can suddenly be experienced with outright fear when equipment fails or bad weather moves in. The same reversal can happen when the stabilizing wheels are taken off the bike of a 5-year-old or when the big bad wolf growls in a cartoon.

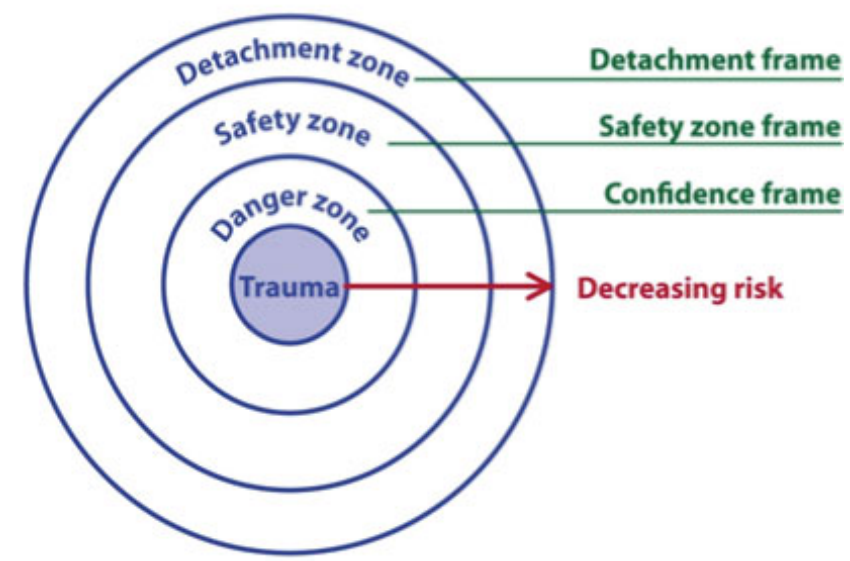

Figure 7. Protective frames as described by Apter (2007a)

Design for play benefits from the awareness of differing preferences for protective frames within and over different persons. Changes within a person are partly due to gaining skills or understanding. The first ride on a bicycle without stabilizers can cause fear but after a while it will be experienced as perfectly safe and new challenges need to be found to increase excitement and danger by, for example, riding down steep hills. Design supporting this dynamic process will reach wider audiences and sustain attention for longer. Figure 8 gives an example of a water toy designed with this idea in mind.

Module 4: Play and excitement. Playful activity is often driven by increasing excitement in any possible way. The increase in arousal caused by incongruity, ambiguity, unpredictability, or silliness can be enjoyed and embraced in a playful state while they are experienced as distracting and annoying in a serious-minded state. Design ideas for play in this sense occupy a possibility space complementary to design for a telic state.

Apter (2002) proposed a number of interdependent psychological strategies to cause or increase excitement:

- exposure to arousing stimulation (e.g. at a rock concert),

- fiction and narrative (stepping in the shoes of characters),

- challenge (any type of competition or skill),

- exploration (finding the unknown),

- negativism (rebellious behavior),

- facing danger (playing with the sense of control),

- cognitive synergy (embracing ambiguity).

With the exception of synergies, the seven ways of increasing arousal and excitement are rather obvious. Cognitive synergies are experienced when an object, situation, or event has opposite or incompatible characteristics which leads to striking and surprising experiences (Coulson, 2002). 


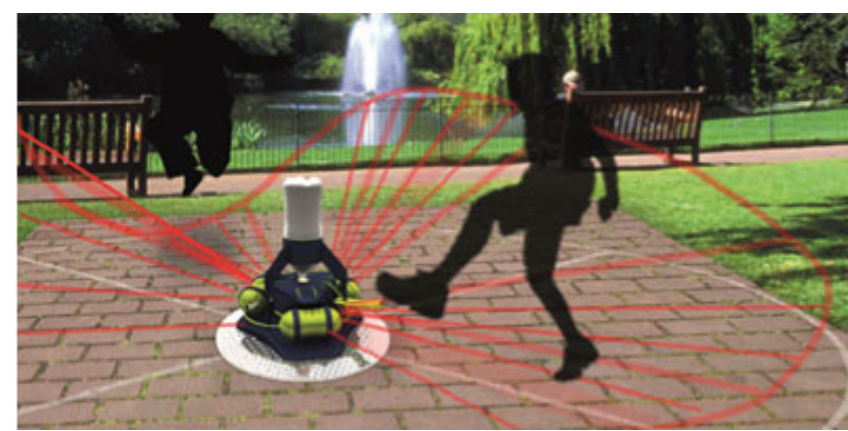

Figure 8. Spinning water toy.

Design by Bob van Meiracker and Sander van Roosmalen. Do you dare risking to get wet? This spinning water toy consists of a water bottle that is connected to a spinning spray nozzle. After it is filled with water and connected, air is pumped into the bottle. The spray nozzle starts to spin and spray water around, until finally the bottle comes loose and shoots off like a rocket. The red lines in the picture indicate the variety of directions the water jet can take. Players can influence the angle of the water nozzle and thus the height of the water jet by kicking the pedal below the bottle. However, the nearer they come to the bottle the higher the chance to become soaked in water. Children are free to choose their distance from the toy and with it control their level of excitement in balance with their experienced safety. They are free to shape their interaction with the toy as well as with each other (being passive spectators, encouraging others, entering the spraying zone, kicking the pedal) and by doing so create many ways to play guided by their changing motivational states.

Arcimboldo's faces made from fruit are a good example, as shown in Figure 9 (Kriegeskorte, 1994).

Looking at the excitement-increasing strategies in the context of the four motivational dimensions in Figure 1 reveals some close connections. "Negativism" is related to the motivational dimension of Rules while "Challenge" refers to the dimension of Transactions. "Fiction and narrative" relates to the dimension of Relationships. The idea of synergies opens up interesting avenues because one could try to create play contexts in which the opposites of each dimension could become the seemingly incompatible aspects of an object, situation, or event. Design for play could evolve from an idea to defy rules in order to play by the rules; or the need to empathize with others players in order to focus on individuality; or to defeat an opponent through co-operation.

Integration of Modules 1-4. Using reversal theory to its full potential means to integrate the different modules. Any play experience can be described with respect to all four modules. A solution space for play-related design can be created using isolated modules or any sequence or hierarchy

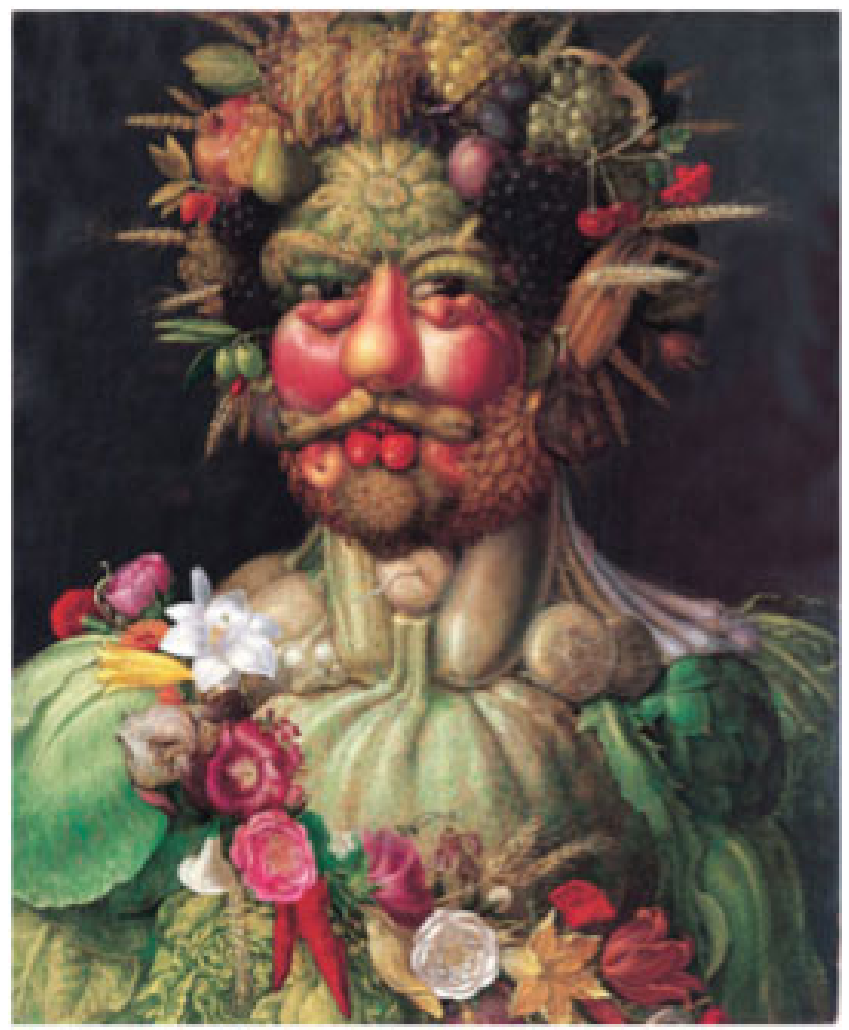

Figure 9. Cognitive synergy in a portrait of Rudolf II / collection of fruits.

Painting by Giuseppe Arcimboldo, 1590-1591. For play, the egg-and-spoon race is based on synergy: running and balancing an egg are two distinct yet ubiquitous activities. However, when combined they provide a surprising challenge to integrate requirements for speed and fine-tuned balance. The bottle bank in Figure 3 is an example of a design using synergies by coupling undesirable behavior with desirable outcomes.

of them. Changing, for example, the sequence of using the modules will change the leading aspects and with it the constraints and degrees of freedom of a design space. The complexity of the concept opens up areas for thought experiments and creates unusual design spaces.

Figure 10 indicates a number of ways to integrate the course modules in the course of idea development. Each module can be used as starting point. Some of the relations between the modules are indicated by arrows, indicating possible lines of thought to follow during ideation. For example, giving students a design topic of "Fun with fears" implies starting with Module 2, taking into account reversals between excitement and anxiety at high arousal levels. Module 1 then could be used to identify dimensions of experience for application. Module 3 would come into consideration 
when trying to design a situation that meets differing needs for feeling safe, yet excited. Module 4 provides a number of approaches to induce excitement.

\section{Results Part Two: Communicating Reversal Theory to Design Students}

As mentioned before, the above representation of reversal theory concepts was shaped through repeated presentation and feedback between psychology and design tutors and participating students over the three deliveries of the design course. Below is a summary of seven general tendencies in the process of familiarising with and utilising the theory, its interaction with the design process and the design results, which were reported before in more detail by Gielen, van Leeuwen and Westwood (2011).

Design as dialogue. The dominant finding of this explorative project is the bi-directional nature of the process. Both psychologists and designers stepped out of their own professional sphere: designers questioning the theory and psychologists reacting on design sketches. Both contributed to the translation of reversal theory, in terms of interaction with products, and into product characteristics. Design students used their design output (such as criteria, scenarios, design sketches) as embodiments of their notions on the theory. The psychologists then used these materials to recognize (mis)conceptions and as starting points for discussing elements of the theory, relations between them, and the consequences for the dynamics of the resulting play behavior. It has been a true dialogue, one in which students used design as their language. It has been in this dialogue that the following six themes have become apparent.

Involvement. Students are willing and indeed enthusiastic about trying out the value of new theories for their design thinking. Being educated as generalists who need to collect and integrate specialist information in each project, they easily accept the theories as a possible tool for analysis and a source of understanding child behavior.

Fragmentation of the theory. Students demonstrated difficulty in dealing with the theory as a holistic perspective. Initially many of them used superficially understood elements of the concept without awareness of their interconnectedness. A large part of the psychologists' effort was directed at stimulating the recognition of reversal theory as a more coherent and complex whole.

Schematic thinking. In the case of arousal states students tended to focus their design ideas at the extremes of arousal in either telic or paratelic states. However, less extreme arousal states occur more frequently and can be longer sustained in both states. Design effort should address less extreme arousal levels and the prevention or support of potential reversals between telic and paratelic states. It was also difficult for students to switch their design focus from one level of arousal or one motivational state to a range of each, thereby handing over control of action to the children rather than trying to tightly determine action by design and instructions.

Dealing with subjectivity. The theory discerns between modes or states of mind. These are subjective phenomena. For example, a "fearful" situation is only perceived as fearful by those who are susceptible to its dangerous characteristics. One cannot determine such a state of mind. In the psychological discourse, it may be common knowledge that any description of psychological states refers to a possibility or probability of a person being in that state, but many design students attempted to apply theory prescriptively. Awareness of the need to hand over control of actions to the user in play was an eye-opener for many students.

Designing for emotional states. Typically students focus on toys as tools for an activity and often consider pleasantness or "fun" as a function of the activity. Reversal theory made them reflect more on the function of a toy as a tool for active self-regulation of more complex emotional and motivational states. An example of this can be found in the design of another "quiet museum toy," shown in Figure 11.

Inspiration. Students found, if not a coherent new perspective, at least parts of explanations for child behavior and play needs that they otherwise would have remained unaware of. In these cases the theory sparked and guided their creativity in unforeseen directions. For instance, the seven strategies for creating arousal mentioned in module 4 provided such direct pointers for design directions - whether linked to the core of the theory or not. The tendency in working with these seven strategies was to take the ones that were most familiar or most clearly related to arousal. Used in isolation this did not lead to the creation of new forms of play - it reconfirmed existing ideas rather than challenging them. Elements of motivation that are generally seen as less desirable (such as negativism/rebelliousness) often proved more fruitful in idea development. For example, a student group explored opportunities for forbidden actions by placing them in a desirable context and designed the bottle bank depicted in Figure 3. Students were pointed by reversal theory towards an area of motivation they had not allowed themselves to explore before.

\section{Discussion}

We presented reversal theory concepts to students in relation to design for play and explored the appropriation of the concepts by the students. We will discuss the potential of the concepts for students of design as well as issues of effectively communicating the concepts to students.

\section{On the Value of the Reversal Theory Presentation}

The first part of the results section is a contextualised presentation of reversal theory principles related to play. We also presented a number of examples of design outcomes 


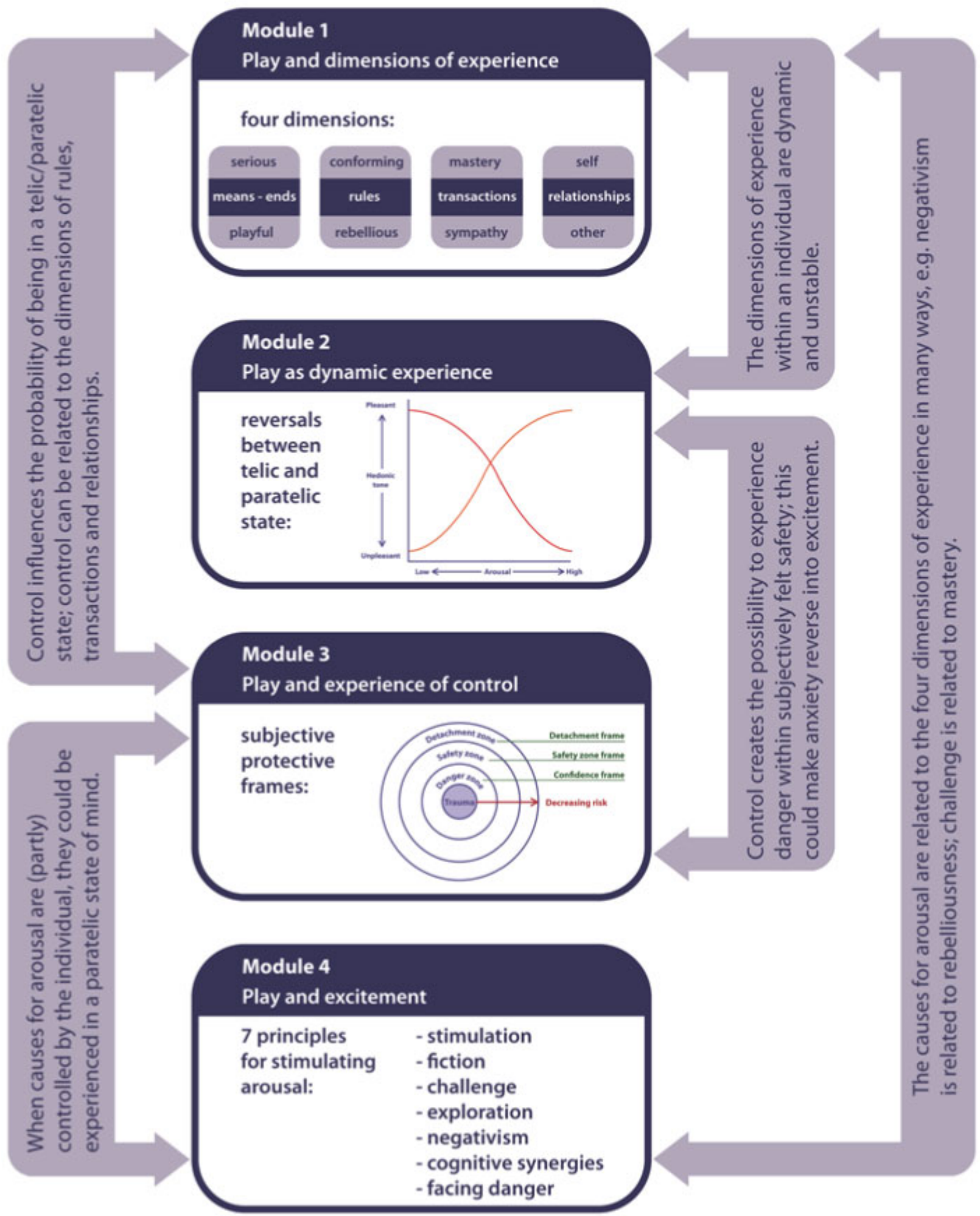

Figure 10. Scheme of Modules 1-4 and examples of relations to be used as 'lines of thought' for their integration. 

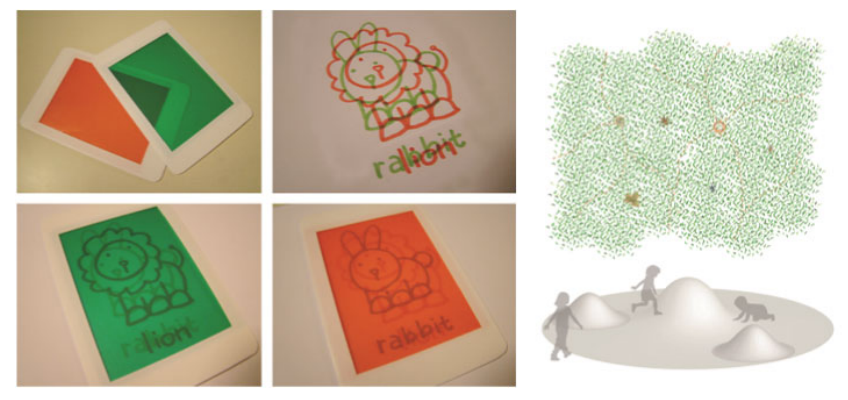

Figure 11. Quiet museum toy.

Design by Chandra Rinie Pudjiatie and Novi Rahman. The 'quiet museum toy' consists of red and green transparent filter frames (left); and an intricate print of overlaying red and green patterns on walls and floor of a museum room (top right). The patterns depict very detailed graphic stories along lines over floor and walls. The filters can be used to block one color print and thus unveil the other one. For this, the color filter needs to be held in the hands and pushed against the walls and floor. To discover the storylines, children crawl around with the frames pushed to the surface (below right). The aim here is to create an experience of quietness and recharging within the hectic atmosphere of a children's museum. All elements of the toy are directed towards bringing the child close to the walls, slowing down movements, studying the details and focusing on what is visible within the small frame. In their description of the use of the toy, the students mention that the almost meditational quality of the experience is encouraged by reducing the state of arousal of the child: they argue that all the design decisions are directed towards slow, gradual, focused, solitary, quiet behavior. The pursued emotional state of the child is leading and the play activities follow from it.

built on these principles. The question of whether an equivalent quality of design ideas could have been achieved without a deeper understanding of reversal theory, using for instance only the graphic presentation of the four modules (Figure 10), cannot be clearly answered at this point. However, in the process described, the graphic representation in Figure 10 functioned as a reference to more detailed information, not as its replacement.

Examples of student designs show openness to changing motivations during play. Exploring this in line with our critique of static developmental overviews would provide useful insights about recommended use of the modules. Another step for further research would be to compare design ideas resulting from specific aspects in order to better understand their specific influence on design ideas. Longer teaching periods would allow us to explore the four modules of reversal theory and their combinations in such a way.

\section{On the Value of Tutor - Student Interaction}

Providing material that explains a psychological concept within a design context helped students to focus and learn about the theory linked to their intentions and existing expertise in design. This saved time and increased the effectiveness of the psychological information. Understanding still was not instant, but the discussions were from the beginning focused on the meaning of the concepts for design. Students could pinpoint their problems in understanding much more precisely than by using general reading.

One element that we have found to be particularly helpful in this process was the use of prompted and spontaneous links to students' personal experiences related to reversal theory concepts. They provided an illustrative medium for understanding as well as an instant check of the external validity of the concept. This empowered students and was often crucial for their decision to implement the concept.

\section{Depth of Knowledge Versus Design Application}

Design, and especially the analysis of design problems, is an activity characterized by the merging of knowledge from many different domains and sources. Designers are trained to filter and select what is of value or brings inspiration without becoming an expert in all these knowledge domains. The quality of the resulting design depends on the full spectrum of criteria that need to be met, not only on the psychological effects it produces. To judge the quality of a designer's work solely by psychological standards is not appropriate. The presented case study, however, aimed to explore the understanding as well as the use of reversal theory. We have tried to monitor depth of knowledge apart from design inspiration and have observed that students tried to understand psychological concepts immediately in the context of design before understanding them in isolation. While this test of "usability" of the concepts for design is an effective strategy, it also contains the danger of using a premature understanding and losing out on possibly more relevant or inspiring parts of the concepts. This ultimately diminishes interdisciplinary integration and transfer to other design contexts. We would argue that in cases where it is not the intention of designers to use the full potential of a theory, they at least needs to be aware of this limitation. They must not be misled (or mislead others) into thinking that their pick of reversal theory's inspirations represents the full significance of reversal theory.

In considering the appropriate depth of knowledge, the eagerness of design students to engage with psychological theories such as reversal theory needs to be matched with sufficient understanding of the needs of designers by psychologists. 


\section{Broader Significance}

In this report we have documented a number of opportunities and issues related to the transfer and use of reversal theory concepts by design students. Whether the chosen processes of transfer apply more generally to psychology concepts or the social sciences domain is an interesting theme for further research. Some insights are in accordance with earlier findings from applying Winnicott's concept of transitional objects in design projects (van Leeuwen and Westwood, 2010). Building on the experiences from the current case study we would need to broaden our efforts to other theories and domains. For now, we propose to apply the criteria presented at the beginning of the results section for bringing psychology concepts into the design context. We encourage the exchange of experiences on this issue, as it will support further advancement of the design profession.

\section{Conclusions}

Design for play is predominantly informed by a rather static notion of children using typologies, average agespecific skills and needs. The project reported here employed reversal theory to help students of design to embrace a more individual, contextualized, and dynamic view of children's motivation to play.

A design-efficient yet complex understanding of reversal theory was presented to students through close integration of concept description and design examples. Describing the theory in the form of modules aimed to create a range of distinct entry points to aspects of the theory in the context of play that can be used either in isolation or in combination. For designers - either in the analytical or ideation phase of design - this presentation enables a choice of different anchors, prioritizations, and outcomes. A summary graphic representation of these modules supported navigation of reversal theory aspects, reference to earlier discussions, and design choices.

Applying reversal theory altered students' focus from general fun and excitement to more concrete ideas regarding play as a dynamic process. Widely varying solution spaces were opened up that students had not recognized before. A marked change in students' thinking was that in order to accommodate a range of motivations and levels of arousal, design for play cannot pre-determine one fixed set of actions but needs to invite children to actively take control and decide how to relate to the design.

The above-presented description of reversal theory is not more than an iteration in the process to make psychological research more accessible for students of design. Systematically comparing the effect of different concepts and their presentations on quality and quantity of design ideas for play will shed more light on the effectiveness of the presented work. We hope to have created the starting point for a pro- ductive interdisciplinary dialogue in the realm of design for play and with it the chance for inspiration and invention.

\section{References}

Ackerman, E. K. (2004). Constructing knowledge and transforming the world. In M. Tokoro and L.Steels (Eds.), A learning zone of one's own: Sharing representations and flow in collaborative learning environments (pp. 15-37). Amsterdam: IOS Press.

Acuff, D. S., Reiher, R. H. (1997). What kids buy and why: The psychology of marketing to kids. New York: The Free Press.

Apter, M. J. (1991). A structural phenomenology of play. In J.H. Kerr \& M.J. Apter (Eds.), Adult play: A reversal theory approach. Amsterdam: Swets and Zeitlinger.

Apter, M. J. (2002) (Ed.). Motivational styles in everyday life. A guide to reversal theory. Washington, DC: American psychological association.

Apter, M. J. (2003). On a certain blindness in modern psychology. The psychologist, Vol. 16, Issue.9, 474-475. doi: 10.1177/1476718X09345393

Apter, M.J. (2007a) Reversal theory: The dynamics of motivation, emotion and personality, 2nd. Edition. Oxford: Oneworld Publications.

Apter, M. J. (2007b). Danger. Our quest for excitement. Oxford: Oneworld Publications.

Bekker, M. M. and Antle, A. N. (2011). Developmentally situated design (DSD): A design tool for child-computer interaction. Proceedings of conference on human factors in computing systems (CHI '11), Vancouver: ACM Press. doi: 10.1145/1978942.1979312

Bekker, M.M., Barendrecht, W., Markopoulos, P. and Read, J. (2014). Teaching interaction design and children: Understanding the relevance of theory for design. Interaction design and architecture(s) journal, N.21, 2014, 9-24. (http://www.mifav.uniroma2.it/inevent/events/idea2010/ index.php? $\mathrm{s}=10 \& \mathrm{a}=11$ )

Boeijen, A. G. C. van, Daalhuizen, J. J., Zijlstra, J. J. M. \& van der Schoor, R. S. A. (Eds.) (2013). Delft design guide. Amsterdam: BIS Publishers.

Burghardt, G. M. (2006). The genesis of animal play: Testing the limits. Cambridge: MIT Press.

Costello, B. \& Edmonds, E. (2007). A study in play, pleasure and interaction design. Proceedings of the 2007 conference on Designing pleasurable products and interfaces. New York: ACM. doi: 10.1145/1314161.1314168

Coulson, A. S. (2002). Cognitive synergy. In: M.J. Apter (Ed.) Motivational styles in everyday life. A guide to reversal theory. Washington, DC: American psychological association. 229-248.

Crabtree, A., Rouncefield, M. \& Tolmie, P. (2012). Doing design ethnography. New York: Springer. 
Csikszentmihalyi, M. (2008). Flow: The psychology of optimal experience. New York: Harper.

de Valck, M. (1996). Het speelgoedboek. Eerste hulp bij het kiezen van speelgoed. Leusden: Uitgeverij Vroegindeweij.

Gielen, M. A., van Leeuwen, L. \& Westwood, D. (2011). Designing for the real child. Toy designers and psychologists in dialogue on reversal theory. Proceedings of IASDR 2011, Delft, The Netherlands. ISBN 978-94-6190-718-9

Hunicke, R., LeBlanc, M., \& Zubek, R. (2004). MDA: A formal approach to game design and game research. Proceedings of the challenges in games AI workshop, Nineteenth national conference of artificial intelligence. San Jose: The AAAI Press. http://www.aaai.org/Press/Proceedings/aaai04.php

Kerr, J. H. \& Apter, M. J. (1991). Adult play. A reversal theory approach. Amsterdam: Swets \& Zeitlinger.

Korhonen, H., Montola, M. \& Arrasvuori, J. (2009). Understanding playful user experience through digital games. International conference on designing pleasurable products and interfaces, Compiegne, France. doi: 10.1145/2347504.2347531

Kriegeskorte, W. (1994). Giuseppe Arcimboldo. Berlin: Taschen.

Kudrowitz, B. M., \& Wallace, D. R. (2010). The play pyramid: A play classification and ideation tool for toy design. International Journal of Arts and Technology, 3(1), 36-56. doi: 10.1504/IJART.2010.030492

Martin, B., Hanington, B. (2012). Universal methods of design. Beverly: Rockport Publishers.

Rogoff, B. (1990). Apprenticeship in thinking: Cognitive development in social context. Oxford: Oxford University Press, 1990. ISBN: 9780195070033
Roozenburg, N. F. M., Eekels, J. (1995). Product design: Fundamentals and methods. Chichester: John Wiley \& Sons.

Schifferstein, H. N. J. \& Hekkert, P. (Eds.). (2007). Product experience. Elsevier.

Shneiderman, B. (2004). Designing for fun: how can we design user interfaces to be more fun?. interactions, 11(5), 48-50.

Smith, P. K. (2010). Children and play. Understanding children's worlds. Oxford: Blackwell

Sutton-Smith, B. (1997). The ambiguity of play. Cambridge: Harvard University Press.

Tromp, N. (2013). Social Design. How products and services can help us act in ways that benefit society (Doctoral dissertation). Retrieved from Delft University institutional repository (repository.tudelft.nl). doi: 10.4233/uuid:c2e396f0-1f29-4ce1-a827-37d62d0b29f8

van Dijk, G. (2010). Design ethnography: Taking inspiration from everyday life. In: Stickdorn, M. \& Schneider, J. (eds.) This is service design thinking. Amsterdam: Bis publishers.

van Leeuwen, L., Gielen, M. A., Westwood, D. (2012). Controlling experience or experiencing control? Reversal theory \& design for play. Proceedings of 8 th international design and emotion conference, London.

van Leeuwen, L., Westwood, D. (2010). If Winnicott could make toys..., International journal of arts and technology, Vol. 3, No. 1, 57-65. doi: 10.1504/IJART.2010.030493 